University of New Orleans

ScholarWorks@UNO

2015

\title{
Quantifying the Stratigraphic Completeness of Delta Shoreline Trajectories
}

\author{
Robert C. Mahon \\ University of New Orleans, rcmahon@uno.edu \\ John B. Shaw \\ Katherine R. Barnhart \\ Daniel E. J. Hobley \\ Brandon McElroy
}

Follow this and additional works at: https://scholarworks.uno.edu/ees_facpubs

Part of the Geology Commons

\section{Recommended Citation}

Mahon, R.C., Shaw, J.B., Barnhart, K.R., Hobley, D.E.J., McElroy, B. [2015], Quantifying the stratigraphic completeness of delta shoreline trajectories: Journal of Geophysical Research: Earth Surface, v. 120, doi:10.1002/2014JF003298.

This Article is brought to you for free and open access by the Department of Earth and Environmental Sciences at ScholarWorks@UNO. It has been accepted for inclusion in Earth and Environmental Sciences Faculty Publications by an authorized administrator of ScholarWorks@UNO. For more information, please contact scholarworks@uno.edu. 


\section{Journal of Geophysical Research: Earth Surface}

\section{RESEARCH ARTICLE \\ 10.1002/2014JF003298 \\ Quantifying the stratigraphic completeness of delta shoreline trajectories}

Key Points:

- Shoreline completeness presented as a 2-D metric for stratigraphic completeness

- Completeness over all timescales is higher in two dimensions than one dimension

- Constrained end-member forward models are presented for shoreline completeness

Supporting Information:

- Data Set S1

- Text S1

Correspondence to:

R. C. Mahon,

rmahon1@uwyo.edu

\section{Citation:}

Mahon, R. C., J. B. Shaw, K. R. Barnhart, D. E. J. Hobley, and B. McElroy (2015), Quantifying the stratigraphic completeness of delta shoreline trajectories, J. Geophys. Res. Earth Surf., 120, doi:10.1002/2014JF003298.

Received 11 AUG 2014 Accepted 6 APR 2015

Accepted article online 9 APR 2015

O2015. American Geophysical Union. Al Rights Reserved.

\author{
Robert C. Mahon ${ }^{1}$, John B. Shaw ${ }^{1,2}$, Katherine R. Barnhart ${ }^{3}$, Daniel E. J. Hobley ${ }^{4}$, and Brandon McElroy ${ }^{1}$ \\ ${ }^{1}$ Department of Geology and Geophysics, University of Wyoming, Laramie, Wyoming, USA, ${ }^{2}$ Department of Geosciences, \\ University of Arkansas, Fayetteville, Arkansas, USA, ${ }^{3}$ Institute of Arctic and Alpine Research, University of Colorado Boulder, \\ Boulder, Colorado, USA, ${ }^{4}$ Department of Geological Sciences/CIRES, University of Colorado Boulder, Boulder, Colorado, USA
}

Abstract Understanding the incomplete nature of the stratigraphic record is fundamental for interpreting stratigraphic sequences. Methods for quantifying stratigraphic completeness for one-dimensional stratigraphic columns, defined as the proportion of time intervals of some length that contain stratigraphy, are commonplace; however, quantitative assessments of completeness in higher dimensions are lacking. Here we present a metric for defining stratigraphic completeness of two-dimensional shoreline trajectories using topset-foreset rollover positions in dip-parallel sections and describe the preservation potential of a shoreline trajectory derived from the geometry of the delta surface profile and the kinematics of the geomorphic shoreline trajectory. Two end-member forward models are required to fully constrain the preservation potential of the shoreline dependent on whether or not a topset is eroded during base level fall. A laboratory fan-delta was constructed under nonsteady boundary conditions, and one-dimensional stratigraphic column and two-dimensional shoreline completeness curves were calculated. Results are consistent with the hypothesis derived from conservation of sediment mass that completeness over all timescales should increase given increasing dimensions of analysis. Stratigraphic trajectories and completeness curves determined from forward models using experimental geomorphic trajectories compare well to values from transects when subsampled to the equivalent stratigraphic resolution as observed in the actual preserved sequence. The concept of stratigraphic completeness applied to two-dimensional trajectory analysis and the end-member forward models presented here provide novel tools for a conceptual understanding of the nature of stratigraphic preservation at basin scales.

\section{Introduction}

The discontinuous nature of sediment accumulation, coupled with erosional processes, results in the preservation of incomplete records of Earth surface processes in the sedimentary record. The concept of stratigraphic completeness was first described by Barrell [1917] and significantly advanced by Sadler [1981] who defined it as the ratio of specified time intervals represented by sediment to the total time spanned by a stratigraphic section. Completeness in one-dimensional stratigraphic sections has proved to be a valuable tool in our understanding of the sedimentary record by providing general insight into the nature of stratigraphic resolution [e.g., Strauss and Sadler, 1989; Sadler and Strauss, 1990] and into the preservation of sedimentary surface processes across scales [Jerolmack and Sadler, 2007; Schumer et al., 2011]. In particular, stratigraphic completeness provides a quantitative and robust approach to epistemic questions in stratigraphy and in the study of Earth's deep time: what is knowable-and what is fundamentally unknowable-in our understanding of past environments? The concept has been extensively applied to stratigraphic analysis and understanding of evolutionary biology in varying contexts. However, past use of this concept has been confined to the one-dimensional case of stratigraphic columns and preservation of depositional beds in the stratigraphic record [Dingus and Sadler, 1982; Dingus, 1984; Wetzel and Aigner, 1986; Lowenstein et al., 2003; Somerfield, 2006].

This vertical, one-dimensional approach to stratigraphic completeness analysis of sedimentary sections, developed in the context of sediment accumulation rates, is well known to be timescale dependent [Sadler, 1981; Sadler and Strauss, 1990; Schumer and Jerolmack, 2009]. One-dimensional stratigraphic sections representing a single point on a surface through time experience hiatus and erosion over many timescales. Therefore, as the timescale of observation increases, the likelihood of observing erosion and hiatus of varying scales increases, resulting in a negative correlation between accumulation rates and 
timescale of observation [Sadler, 1981; Plotnick, 1986; Sadler and Strauss, 1990]. The metric of stratigraphic completeness, defined as the proportion of time intervals of some specified length that preserve a record of sediment, exhibits an opposite relation such that over longer timescales the probability of capturing intervals in which sediment is preserved increases [Sadler, 1981; Tipper, 1983]. The principles of sediment mass conservation, however, dictate that at higher dimensions, stratigraphic completeness should increase for a given time interval of observation, owing to the fact that sediment removed from or bypassing one location must be deposited somewhere else [Sadler and Jerolmack, 2014].

The forward solution for expected one-dimensional stratigraphic completeness given knowledge of the history of the vertical kinematics of the sedimentary surface is relatively straightforward and is well illustrated by Barrell [1917, Figure 5]. The inverse solution for determining completeness from an ancient stratigraphic section, however, requires a well-established geochronology. This is due to the fact that completeness calculations require direct recognition and temporal constraints on individual hiatuses. Empirical or statistical relations linking expected and observed accumulation rates at various timescales to completeness values [Sadler, 1981; Kemp, 2012] can also be used; however, the requirement of geochronological data remains. These kinds of problems are only compounded by the move from onedimensional to full multidimensional analysis. In such cases the locations, boundaries, and chronologies of whole packages of sediment must now be assessed and constrained, as opposed to working only with individual surfaces along a single vertical transect (e.g., from a simple borehole) in the one-dimensional case [Sadler and Jerolmack, 2014].

For this reason, few published studies have attempted to apply the concept of stratigraphic completeness or develop quantitative methods for describing the completeness of stratigraphy in higher dimensions. In this study, we propose a simple method for using the stratigraphic expression of shoreline migration which records both progradation/retrogradation and aggradation/degradation of a sedimentary surface to explore the potential for two-dimensional completeness analysis.

The record of a shoreline trajectory is determined for this purpose from positions of topset-foreset breaks (see Figure 1) in deltaic strata [Helland-Hansen and Hampson, 2009, and references therein]. A shoreline trajectory as applied in this paper could be observable at the scales of outcrop or core based on changes in grain size or depositional environments. Similarly, a shoreline trajectory could be observed at basin scales from seismic or well-log data such as is commonly done in the analysis of marine sedimentary basins [Helland-Hansen and Martinsen, 1996; Helland-Hansen and Hampson, 2009; Henrickson et al., 2009; Maia et al., 2010]. Moreover, a shoreline trajectory itself is of particular interest in understanding basin history, as shoreline migration rates can elucidate the nature of sediment delivery to the front of a deltaic system through time, as well as base level history. When taken in conjunction with information about the geometries of deltaic deposits (slope of the topset, position of the delta toe, etc.), a shoreline trajectory can help constrain past rates of generation of accommodation space through eustasy or subsidence [Swenson et al., 2000].

The preservation of a shoreline position in the stratigraphic record is explicitly linked to two distinct processes that occur in response to base level fall. The first is the erosion of previously deposited topset-foreset breaks during relative lowstand conditions. Under these conditions, it is possible for some topsets to erode down to a level set by a new, lower (and more basinward) shoreline, thus removing some antecedent shoreline positions from the stratigraphic record (see Figure 2a). However, it is also possible for some locations along a delta to not experience erosion during lowstand thus preserving the previously deposited shoreline markers. These two responses to base level fall are controlled by the locus of channel activity on a delta top. Similarly, lateral sediment transport along a delta front can occur, in which deltaic deposits could prograde off axis of the principle sediment routing system (i.e., offlap; see Figure $2 \mathrm{~b}$ ). Together these two effects can potentially result in similar geomorphic shoreline trajectories giving rise to radically different completeness-timescale relationships. Because of this, any forward model of shoreline completeness must incorporate likelihood of subaerial preservation of topset-foreset breaks as one of its dependencies. Our approach is to explore two end-member scenarios-full subaerial preservation, and zero subaerial preservation of topsets during lowstand-in order to constrain the bounds on shoreline completeness.

The second process that may result in reduction of stratigraphic completeness derives from the stratigraphic filter; the depositional record of a shoreline position might not be observable due to both deterministic and 


\section{AGU Journal of Geophysical Research: Earth Surface}
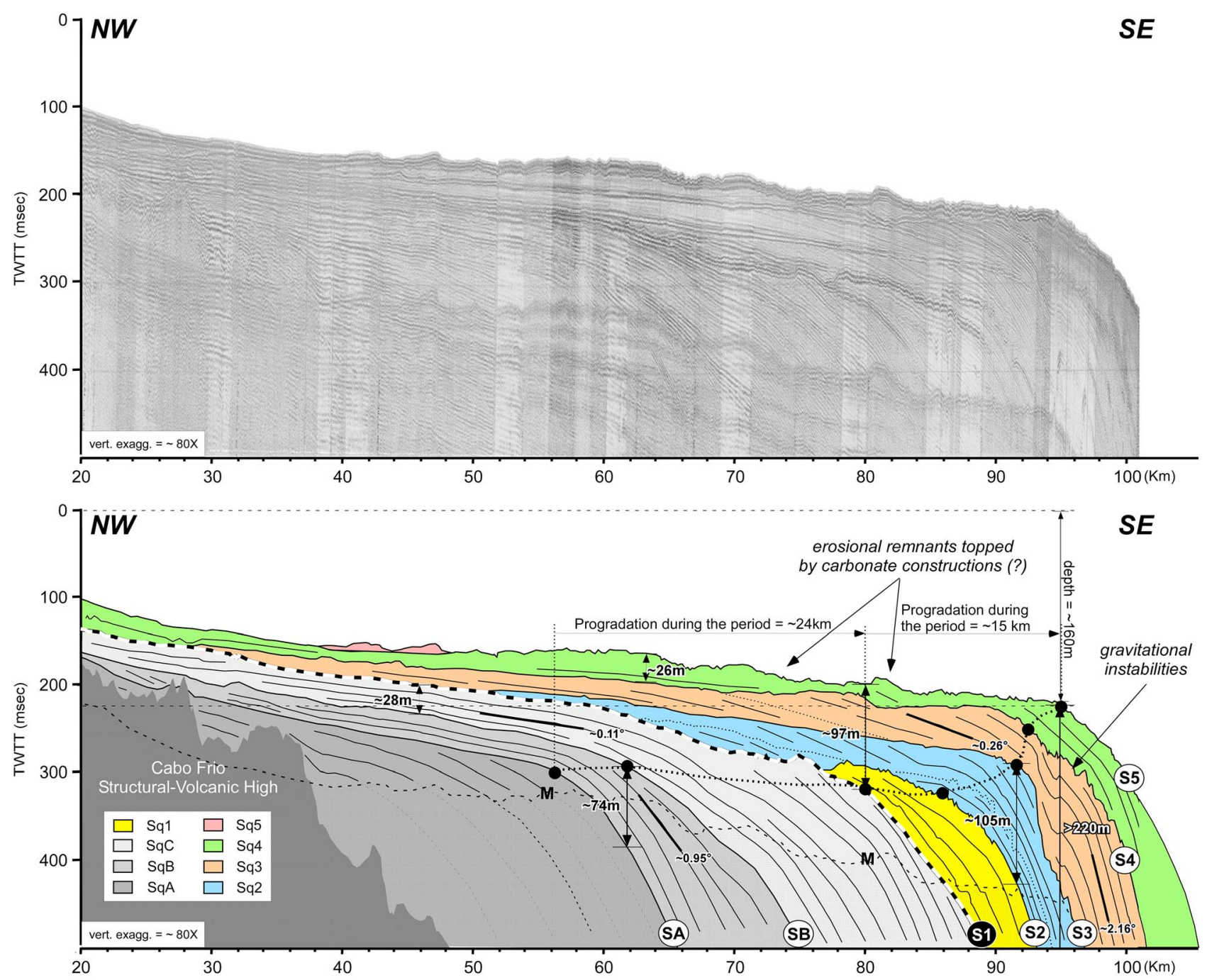

Figure 1. Seismic reflection profile (top) from Maia et al. [2010] (reproduced with permission) showing (botom) an example of shoreline trajectory analysis based on the position of the topset-foreset rollovers.

stochastic controls on the resolution of stratigraphic horizons. Although stratal thickness may be preserved that reflects shoreline migration, a stratal surface allowing for the observation of a topset-foreset rollover position or a set of observable facies associations allowing this determination might be lacking from the depositional record. This is a unique challenge for both the traditional approach of one-dimensional completeness analysis and two-dimensional shoreline completeness analysis, resulting in a potential reduction in completeness. Reductions in completeness through this mechanism should depend heavily on the nature of the sedimentary system, as well as the scales of observation over which the shoreline positions are being determined.

In this paper we develop a theory to quantify the completeness of shoreline trajectories in the stratigraphic record using a timescale-based approach similar to that defined for one-dimensional stratigraphic columns [Sadler and Strauss, 1990; Schumer and Jerolmack, 2009]. A pair of forward models is presented for expected shoreline completeness based on the geometry and kinematics delta surfaces. These models are developed to provide the framework from which investigations of controls on two-dimensional shoreline completeness can be determined from input shoreline kinematics. We present and analyze a fan-delta experiment by applying these forward models to the observed shoreline trajectories. We also test the hypothesis of dimensional dependence of stratigraphic completeness put forward by Sadler and Jerolmack [2014] through a comparison of values of stratigraphic completeness for two-dimensional shoreline trajectories 
a.

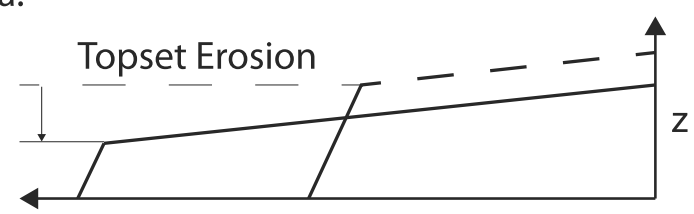

b.

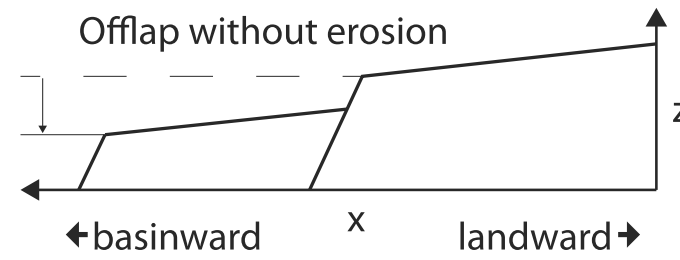

Figure 2. Illustration of the different scenarios for topset erosion/preservation during periods of relative base level lowstand. (a) Base level lowstand is accompanied by offlap, and thus, the antecedent topset and shoreline position are preserved. In contrast, (b) the topset may be eroded during lowstand. These two scenarios may not necessarily be distinguishable given a particular geomorphic shoreline trajectory.

length $T(T=N \Delta t), i$ is an index, and $\chi$ is a measure of the local completeness in each interval determined by the following:

$$
x_{i}=\left\{\begin{array}{ccc}
0 & \text { strata } & \text { are } \\
1 & \text { strata } & \text { absentforinterval }\left(t_{i}, t_{i}+\Delta t\right)
\end{array}\right.
$$

where $t_{i}$ is the age representing the beginning of a time interval such that $t_{1}$ is the oldest age in the entire section being analyzed.

The concept of completeness, as applied to a one-dimensional stratigraphic column can be applied with little complication to the two-dimensional case of a shoreline trajectory. To accomplish this, we introduce a modest variation on equation (1) that accounts for a two-dimensional shoreline trajectory:

$$
C_{\mathrm{sh}}(\Delta t)=\frac{1}{N} \sum_{i=1}^{N} x_{i, \mathrm{sh}}
$$

Where $C_{\text {sh }}$ is the shoreline trajectory completeness, and $x_{i, \text { sh }}$ are the local values of stratigraphic completeness of shoreline positions (i.e., a topset-foreset rollover) defined in a similar way to equation (2):

$$
x_{i, s h}=\left\{\begin{array}{ccl}
0 & \text { shoreline position } & \text { absentfor interval }\left(t_{i}, t_{i}+\Delta t\right) \\
1 & \text { shoreline position } & \text { presentfor interval }\left(t_{i}, t_{i}+\Delta t\right)
\end{array}\right.
$$

Ultimately, shoreline completeness answers the question, "What fraction of geologic time preserves a record of shoreline position, as a function of observation timescale?" This approach allows the calculation of shoreline completeness in a directly comparable way to that of one-dimensional methods, allowing straightforward comparison of differences in completeness in one and two dimensions for delta stratigraphy.

Similar to one-dimensional completeness calculations, the reality of defining an exact age for a particular shoreline position requires constraints not commonly available in the stratigraphic record. Thus, the completeness of trajectories and, in fact, any two-dimensional stratigraphy would likely require a model from which expected completeness could be inverted, as opposed to directly measured. It is with this motivation that we develop two forward models (section 3.2) relating shoreline trajectory kinematics and delta geometry to the preservation potential of stratigraphic shoreline trajectories. These forward models are a prerequisite to any possible inversion of shoreline data and complete stratigraphic analysis. 


\section{Methods}

\subsection{Completeness Calculation}

In this study, completeness is calculated using equations (3) and (4). We use discrete timescales, as opposed to a continuous timescale approach for the sake of computational simplicity, with $\Delta \mathrm{t}$ set at the same interval as the timescale of input trajectory data points. In order to minimize any influence of the timing of the initial period of a section (at $i=1$ ) on the determination of completeness, we suggest that intervals of $\Delta t$ should be set to overlap, as opposed to sequential and nonoverlapping. This is especially important in determining the timescales over which a section reaches $100 \%$ complete (absence of any hiatuses longer than $\Delta t$ ). Sequential nonoverlapping analyses can result in the determination of $100 \%$ completeness at shorter timescales than the length of the longest hiatus if that hiatus partially spans the position of two $\Delta t$ intervals in the analysis. Setting $N$ significantly larger than $T / \Delta t$ minimizes the potential for bias resulting from the arbitrary placement of the position of $i=1$ and results in a more robust sampling of the stratigraphic section of interest.

\subsection{Forward Modeling}

In order to constrain geometric and kinematic controls on the completeness of shoreline trajectories, we present two forward models in which we generate expected stratigraphic shoreline positions and evaluate stratigraphic completeness from a geomorphic shoreline trajectory. These two models provide a predictive framework for shoreline preservation and stratigraphic completeness in order to begin to enable exploration of the potential stratigraphic products of ranges of geomorphic trajectories. The models are developed using the geometry and kinematics of sedimentary surface evolution for deltas in a manner akin to the bed form model of Rubin and Hunter [1982]. The two models differ in how they erode previously deposited material during a sea level lowstand. Because there is no exact constraint of mass balance required in a given cross section, we present two models that bracket the geometric constraints on minimal and maximal erosion conditions.

The first model ("minimum completeness model") removes prior shoreline positions based on the angle of the topset such that all stratigraphy below any new topset is removed; the second model ("maximum completeness model") only erodes preexisting shoreline positions when a new shoreline is generated below and landward of prior positions, such that it only erodes when the shoreline trajectory absolutely requires it without any other assumptions. The combination of these two models allows us to determine the theoretical minimum and maximum completeness for a shoreline trajectory over ranges of timescales. We implement both models in MATLAB, and the model code is available along with comments and run notes in the supporting information.

\subsubsection{Model \#1: Minimum Completeness}

Nonpreservation of shoreline positions through erosion can occur in certain predictable geometric configurations. Specifically, erosion occurs when base level fall causes a drop in topset elevation, removing strata that may contain previous shoreline locations (see Figure 3). This first model creates synthetic stratigraphy based on a simple set of geometric rules for deposition of new stratal packages depending on positions of input geomorphic shorelines relative to antecedent strata in $x(t)-z(t)$ space, where $x$ and $z$ are the horizontal and vertical directions and $t$ is time. Stratigraphic surfaces are generated in a fashion similar to previous geometric shoreline migration models [Swenson et al., 2000; Kim and Muto, 2007; Kim et al., 2009]. The moving boundaries in our model are defined by the input topset and foreset slopes, and the shoreline position, as opposed to the bedrock-alluvial transition, delta toe, and shoreline position of previous models. This simplification is possible because of specific conditions modeled in this paper of a planar basin floor and fixed $x$ position of the delta inlet, although the delta toe is determined to truncate on the topset of previously deposited strata, as is the case with the previous models. Topset and foreset slopes are parameterized in this model depending on the individual system considered, and these surfaces are considered planar.

There are four basic possible relative configurations for shoreline trajectories (see Figure 3): (a) if a shoreline is higher and more basinward than existing strata, a whole new stratigraphic package is created; (b) if the shoreline is higher but more proximal than the rollover of a subjacent stratum, a topset is created, and a foreset downlaps onto the existing surface; (c) if a shoreline is more distal but lower than any existing rollover, the top of the existing delta is truncated where the topset would intersect it (given the specified 
a. Shoreline regresses with base level rise

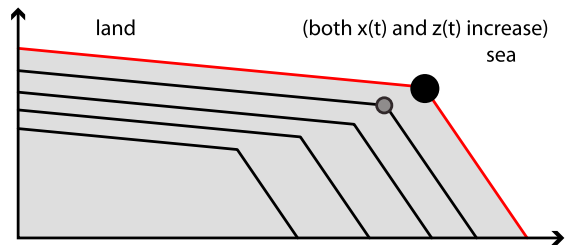

c. Shoreline regresses with base level fall

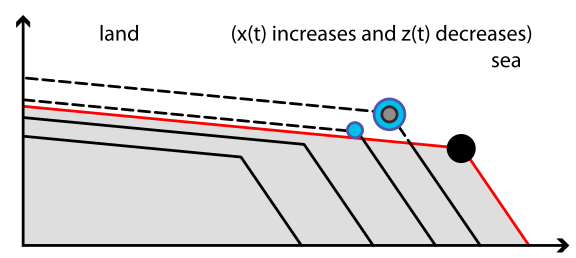

Position of Shoreline

○ prior time step

current time step

- shoreline not preserved b. Shoreline transgresses with base level rise

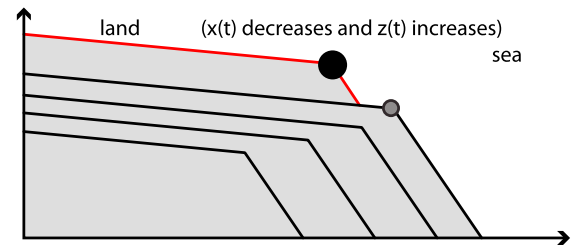

d. Shoreline transgresses with base level fall

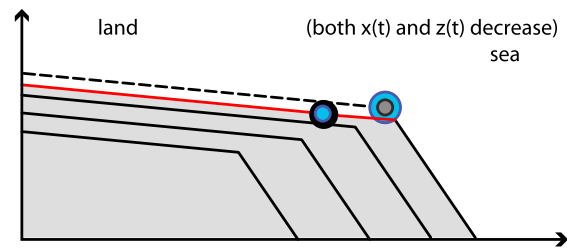

Figure 3. Illustration of shoreline completeness model treatment for each possible shoreline trajectory for the minimum completeness end-member model. New strata are generated and eroded depending upon specification of the angles of the topset and foreset. ( $a$ and $b$ ) Under circumstances when base level rises, a new stratal package is deposited, and prior deposits/shoreline positions are preserved. ( $c$ and d) When the base level drops any prior deposits at elevations above the new topset elevation are removed and are not preserved. If the shoreline regresses as base level drops, it creates a sediment package with a preserved shoreline as shown in Figure 3c, but if the shoreline transgresses with base level fall (an uncommon trajectory), no shoreline is preserved.

topset slope), but the foreset and distal parts of the topset are still drawn outboard of existing strata; and (d) if the shoreline is within a preexisting stratal package, the top of the delta is eroded to the topset angle, and no new sediment package is created and that time period is not considered preserved.

This model assumes that topsets will always be eroded during lowstand, which is not necessarily required (see Figure 2). Thus, this model is taken to represent one end-member case in which maximum erosion, and therefore minimum stratigraphic completeness values, would be obtained. In the case for which erosion of delta topsets is known to have occurred, this model should provide an accurate representation of shoreline erosion and completeness. However, this model will overpredict the amount of erosion and underpredict completeness for sections where topsets were not always or not entirely removed during lowstand. Thus, a second end-member model is required to fully constrain the forward problem for shoreline completeness.

\subsubsection{Model \#2: Maximum Completeness}

A second end-member model for maximum completeness is developed in a similar conceptual framework to the first; however, it is developed without assumptions regarding delta geometries (topset/foreset angles) and is solely driven by kinematics of input shoreline trajectories. This model differs from Model \#1 in how it handles erosion during periods of base level lowstand. In this model, stratigraphic expressions of shoreline position are only eroded when shorelines cross into the domain below and landward of an antecedent shoreline (see Figure 4). This occurs, for example, when a base level fall is followed by base level rise in which the shoreline trajectory tracks an erosional surface (e.g., Figure 4b). This is in contrast to the previous model, which always erodes preexisting stratigraphy above any topset generated based on the position of new shorelines and the topset angle specified by the user (see Figure 3). In other words the principle difference then could be described as whether a model permits offlap of sedimentary sequences or zero net transport (as is the case in Model \#2) or requires erosion during lowstand under all circumstances (as in Model \#1).

The second model only erodes a previous shoreline position when a trajectory explicitly requires it. In this model it is plausible that in some cases, particularly when a trajectory ends on a lowstand, erosion of 


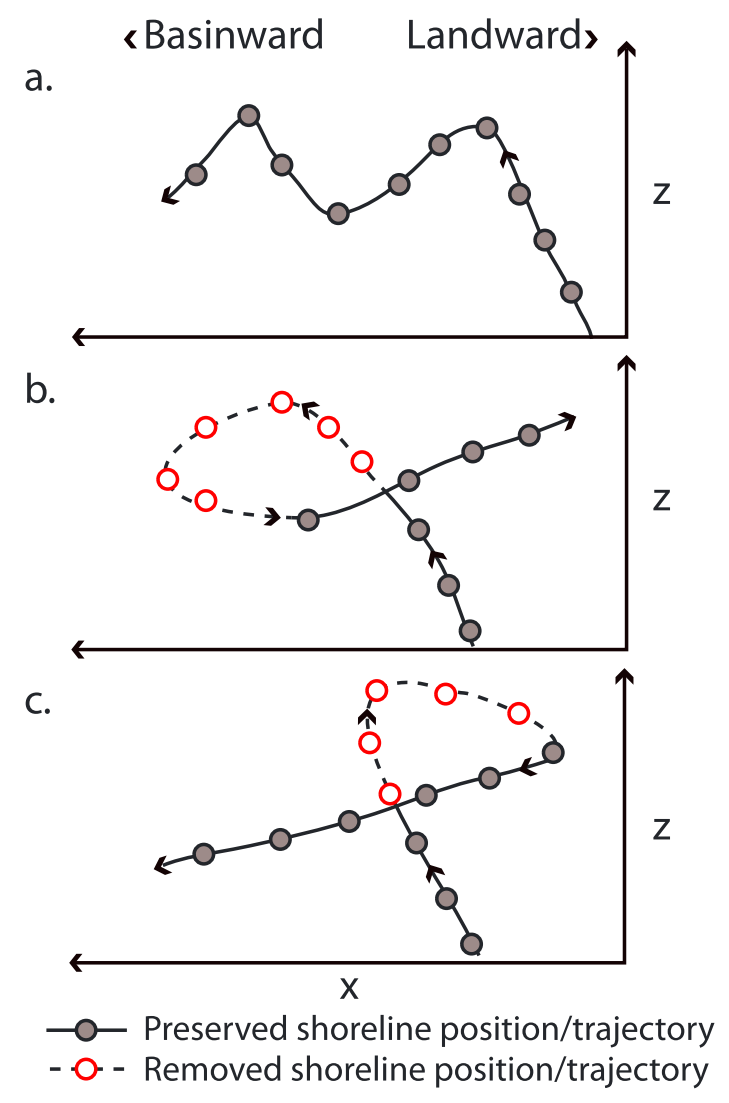

Figure 4. (a-c) Illustration of delta completeness model treatment for the maximum completeness end-member model. Prior shorelines are removed only if they are above and basinward of following shoreline position.

reduce the amount of data incorporated into
completeness analysis, meant to approximate seismic observations and outcrop sections. We also present a random sampling filter as a baseline for comparison.

The first method ("spatial/seismic") specifies a minimum spatial scale between sampled horizons below which a sedimentary package is treated as "invisible," and not counted toward section completeness. In other words, this method is biased below a characteristic average separation between recorded stratal boundaries. Although it does not actively seek to preferentially sample "bigger" intervals, the result is that proximity of intervals filters out the smallest intervals. This is intended to approximate a characteristic thickness at which horizons might be resolved in a seismic profile. As the minimum scale of resolution increases, the number of strata preserved decreases which in turn is expected to influence stratigraphic completeness

The second method ("biggest steps") also subsamples simulated horizons to simulate incomplete preservation, but instead of seeking to create a minimum spacing in final sampled intervals as in the spatial/seismic method, it preferentially samples the thickest recorded beds in the sequence. This is intended to approximate a bias in the record toward times of high sedimentation rate (i.e., thicker beds are more likely to leave a record) and may approximate field observation of a deltaic outcrop (e.g., if beds are mapped from photographs of a large-scale exposure). It is implemented by evaluating the Pythagorean change in position (in both $x$ and $z$ ) of all of the originally preserved shoreline positions from the forward model runs, sorting the list of changes, then selecting only horizons found at the ends of $N$ stratal intervals with the biggest changes.

The third and final method ("random") subsamples simulated horizons at random. The top of each stratum has an equal probability of being selected. This method is included as a null hypothesis but nonetheless is still physically plausible. For example, this scenario might arise if the section is known in sufficient detail 


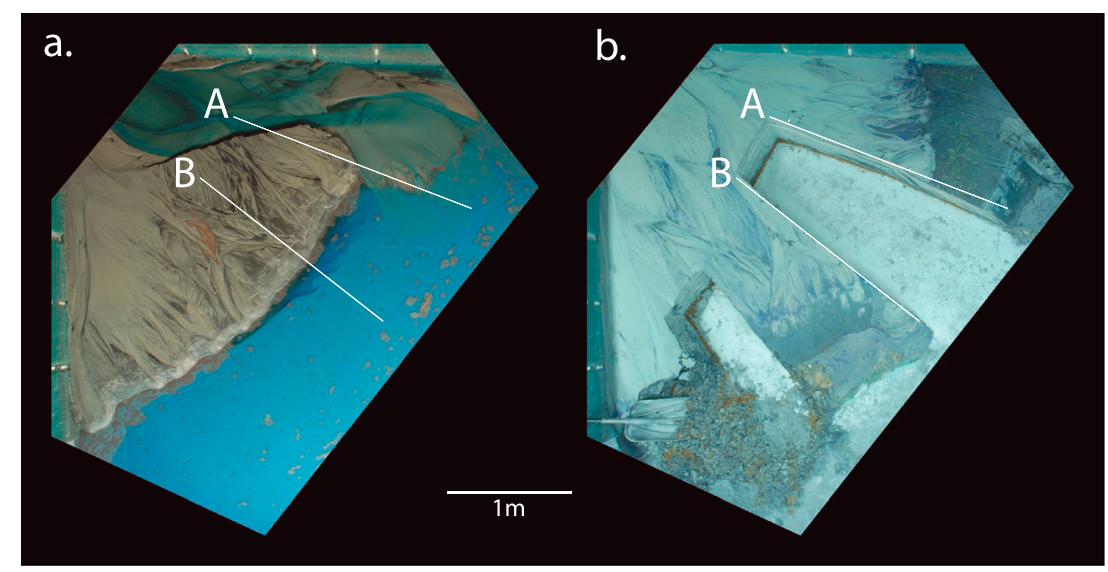

Figure 5. Overhead images of experimental delta at (a) run time of approximately $33 \mathrm{~h}$ and (b) after completion of experiment and trenching of down depositional dip transects. Lines labeled A and B are locations of transects from which geomorphic and stratigraphic shoreline trajectories were analyzed.

and at sufficient resolution that effectively all strata have been identified and there is no systematic bias against thinner beds. This method also results in a bias toward nonpreservation of beds where shoreline migration was rapid, and thus, few input geomorphic shoreline positions are represented over a large distance (such as during transgression). This can result in a potentially appropriate omission of stratigraphic shoreline positions where the shoreline tracked a prior surface without deposition.

\subsection{Experiment}

To understand the geometric and kinematic constraints on shoreline preservation under fully determined conditions and to provide inputs for validation and exploration of the forward models described above, an experimental Gilbert-type delta (see Figure 5) was developed at St. Anthony Falls Laboratory (SAFL) at the University of Minnesota. The experimental tank measured $5 \mathrm{~m}$ by $5 \mathrm{~m}$ by $0.64 \mathrm{~m}$ deep. Sediment used in the experiment was a mix of $70 \%$ quartzose sand (median diameter $110 \mu \mathrm{m}$ ) and crushed anthracite coal (bimodal: 460 and $190 \mu \mathrm{m}$ modal diameters). This mixture has previously been shown to generate clearly resolvable stratigraphic surfaces based on contrasting colors and sediment hydrodynamic properties, with the coal more capable of longer transport distances mimicking a finer grain size due to a significantly lower specific gravity (1.3) than that of quartzose sand (2.65) [e.g., Sheets et al., 2002; Kim et al., 2006].

The experiment was initially set up under constant base level, sediment supply, and discharge conditions for $72 \mathrm{~h}$ to build out the delta deposit; after which point, both steady and rapid changes in base level and rapid changes in sediment/water discharge were then applied over a period of $48 \mathrm{~h}$ (Figures $6 \mathrm{a}$ and $6 \mathrm{~b}$ ). No subsidence was applied. Conditions were chosen so as to result in a record of shoreline migration response to a range of sediment/water discharge and base level scenarios, with the goal of making experimental and model comparisons as generalizable as possible.

Overhead imagery was captured every 30 s throughout the duration of the experiment, and this imagery was used to determine the horizontal position of the shoreline along two "dip-parallel sections" (vertical planar transects selected at positions axial to the delta apex, approximately perpendicular to the shoreline averaged over experimental development; see Figure 5) using code provided in the supporting information and available through the Sedimentary Experimentalists Network Knowledge Base (at www. sedexp.net). Specific locations of the two dip-parallel sections were chosen to reflect the differing response of the delta topset to the period of base level fall, with one transect (river left) experiencing significantly more erosion than the other (river right). Section A was located at $20^{\circ}$ and section $B$ at $40^{\circ}$ radial angles from the river left sidewall of the experimental tank (see Figure 5). Together with the base level history (Figure 4a), a shoreline horizontal $(x)$ and vertical $(z)$ position was resolved at $30 \mathrm{~s}$ time intervals for each transect (see Figures $4 c$ and $4 d$ ). Additionally, 13 high-resolution topographic scans were collected at various times during the experiment, while flow was turned off. After the experiment was completed, the experimental basin was drained and the delta was allowed to dry. The deposit was then 


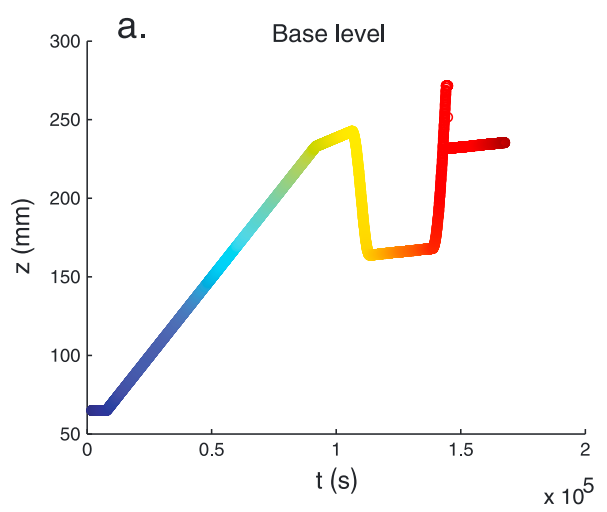

Transect A:
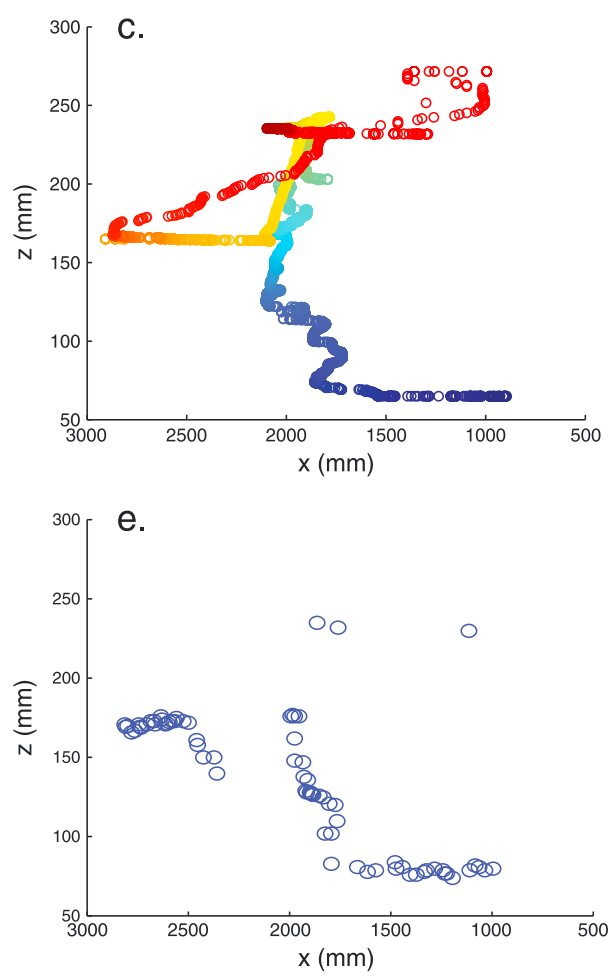

b.

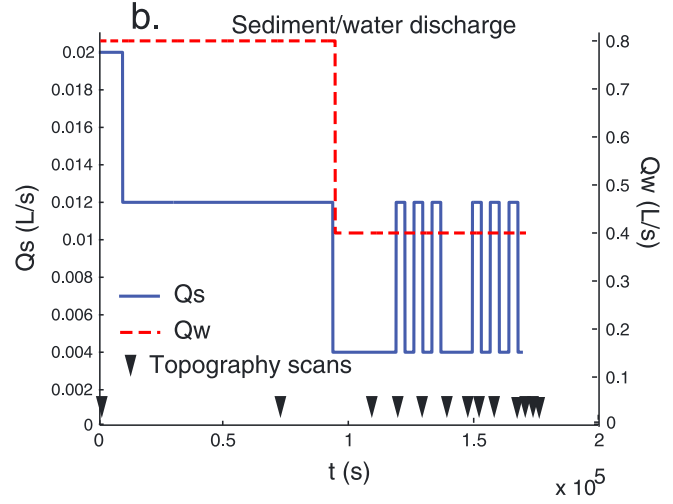

Transect B:
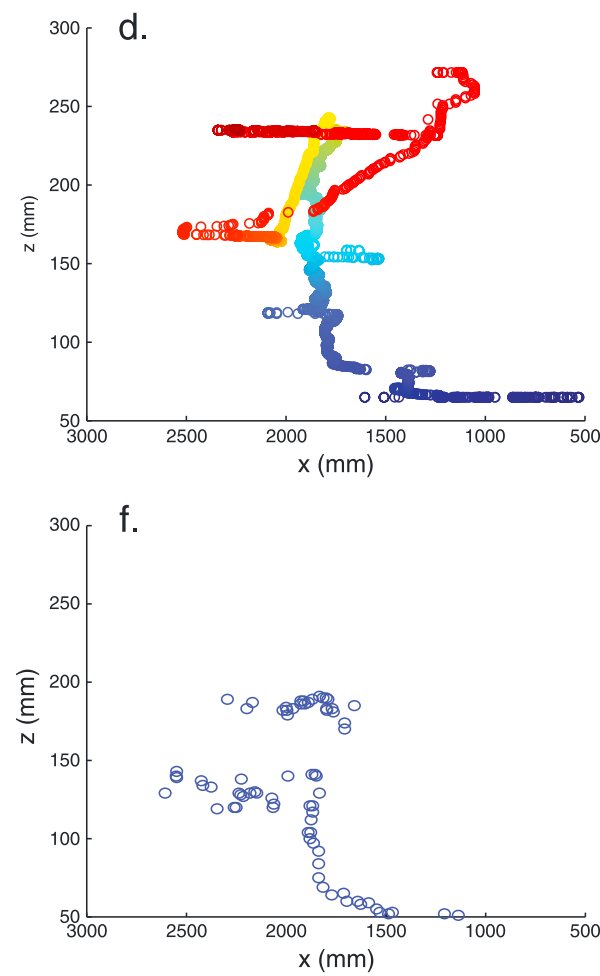

Figure 6. Input conditions and data from experimental delta developed at St. Anthony Falls Laboratory: (a) imposed base level, (b) input sediment and water discharge, (c and d) geomorphic shoreline positions determined from overhead imagery and experimental base levels for transects $A$ and $B$, respectively, and (e and f) stratigraphic shoreline positions determined from topset-foreset rollovers for transects $A$ and B, respectively. Time axis and color scale in Figure $6 a$ serve as the color scale for Figures $6 \mathrm{c}$ and $6 \mathrm{~d}$.

trenched to collect images of dip-parallel cross sections (Figures $5 b$ and 7a). Two dip sections were interpreted using the position of the topset-foreset rollovers as the stratigraphic expression of the shoreline (see Figures $6 \mathrm{e}, 6 \mathrm{f}, 7 \mathrm{~b}$, and 7c).

Next, a "time stamp" was ascribed to each topset-foreset rollover in the stratigraphic record. This was done by comparing $x$ and $z$ coordinates of each rollover to the geomorphic shoreline trajectory, for which $x$ and $z$ are known at the temporal resolution of the overhead imagery $(30 \mathrm{~s})$. This was a manual process and prone to some error. Low-precision results from uncertainty in the exact stratigraphic position of the shoreline as the topset-foreset rollover is rarely a clearly defined feature on scales $<1 \mathrm{~mm}$. Time stamps were assigned such that stratigraphically older rollovers received older time stamps, so relative timing was preserved. While it is impossible to calculate exact error associated with this manual process based on interpretive stratigraphic geometry, we estimate it to be on the order of hundreds of seconds. 

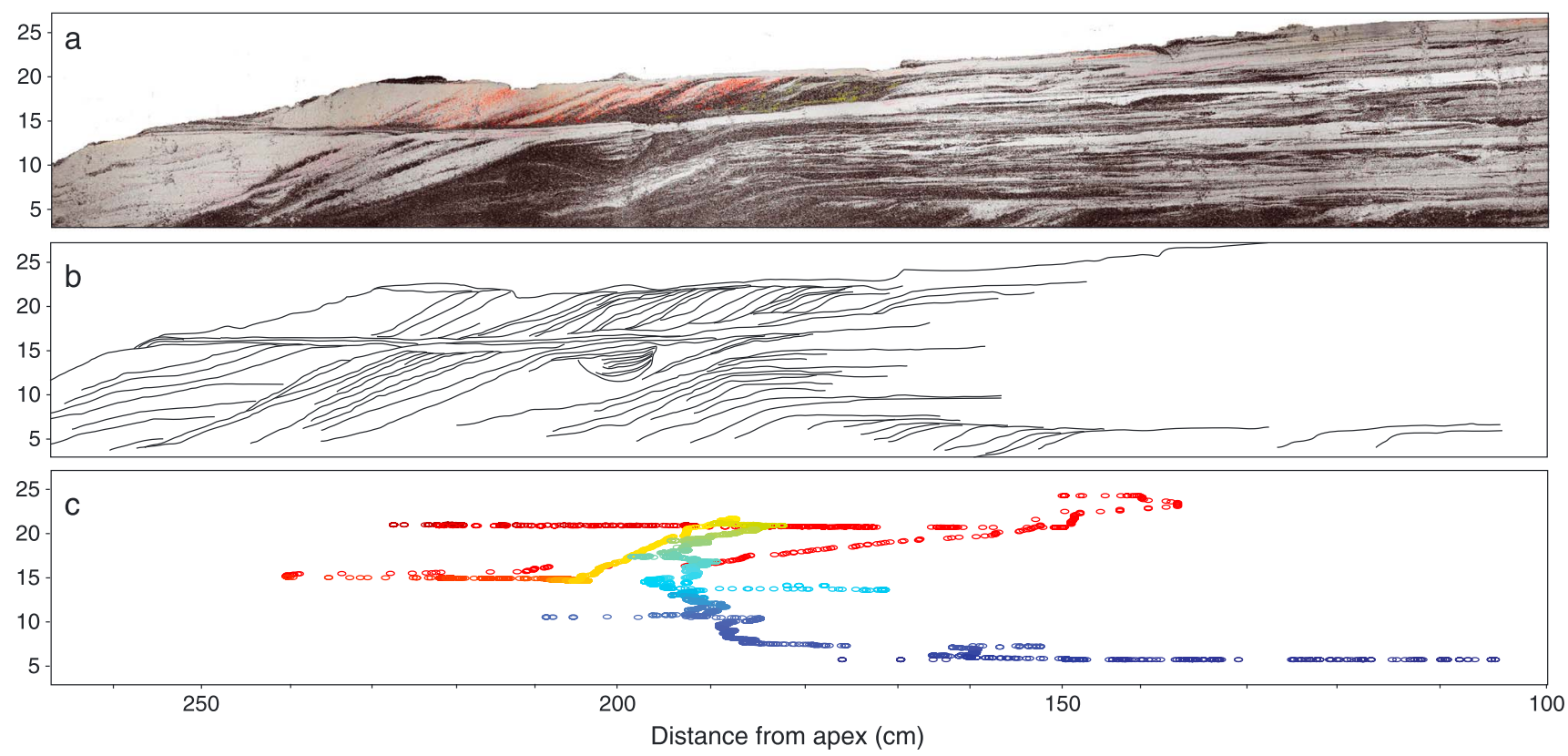

48hrs $36 \mathrm{hrs}$ 24hrs $12 \mathrm{hrs}$

Run time

Figure 7. Experimental data from stratigraphic transect B: (a) photomosaic of down depositional dip stratigraphic section, (b) traces of stratigraphic surfaces used to interpret shoreline positions from topset-foreset rollovers, and (c) comparison of shoreline positions interpreted from stratigraphy with geomorphic shoreline positions extracted from overhead imagery and experimental base level. Temporal information for the stratigraphic shoreline positions is determined from comparison to the known shoreline positions.

\section{Results}

\subsection{Experiment}

In both analyzed transects, the experimental delta experienced an initial period of progradation, followed by an aggradational period tracking applied base level rise. During this interval, delta shoreline positions gained approximately $170 \mathrm{~mm}$ in height with generally little progradation. Exact shoreline positions were strongly influenced by delta top channel dynamics and vary between transects. During the following period of base level fall (at $t=1 \times 10^{5} \mathrm{~s}$ ) incision and channel entrenchment occurred, primarily along the river left portion of the delta (see Figure 5). This incisional channel remained entrenched during the entire period of base level fall, resulting in a significant difference in shoreline response across the delta as portions experienced relative stasis, while others experienced erosion of the topset accompanied by forced regression and progradation. During the subsequent period of rapid base level rise, shorelines generally regressed across the delta topset or antecedent foreset, followed by a final period of progradation.

Shoreline trajectory resolution was strongly influenced by the minimum thicknesses of resolvable stratigraphic horizons, seen to be approximately $1 \mathrm{~mm}$, a limit set by the ability of our experimental system to generate stratigraphy on the order of 2-3 grain diameters. Thicknesses of stratigraphic horizons varied significantly, influencing our ability to resolve shoreline positions from the experimental delta: we were able to resolve 73 shoreline positions in transect $A$ and 74 in transect B (see Figures 6e and 6f).

The distribution of shoreline completeness was calculated over a range of timescales from shoreline positions determined from stratigraphy using equations (3) and (4) (code provided in the supporting information), and these distributions are shown in Figure 8. Shoreline completeness decreased as resolution timescale decreased (see Figure 8). This result is consistent with requirements of one-dimensional stratigraphic completeness analyses. As finer timescales are analyzed, completeness decreased as well [Sadler, 1981]. In each case, shoreline completeness approached 1 (100\% completeness) as the resolution timescale approached the length of the experiment $\left(1.66 \times 10^{5} \mathrm{~s}\right)$. The stratigraphic record preserves the shoreline trajectory in 73-74 preserved rollovers, with an average timescale of resolution of $2.24 \times 10^{3} \mathrm{~s}$. This is 


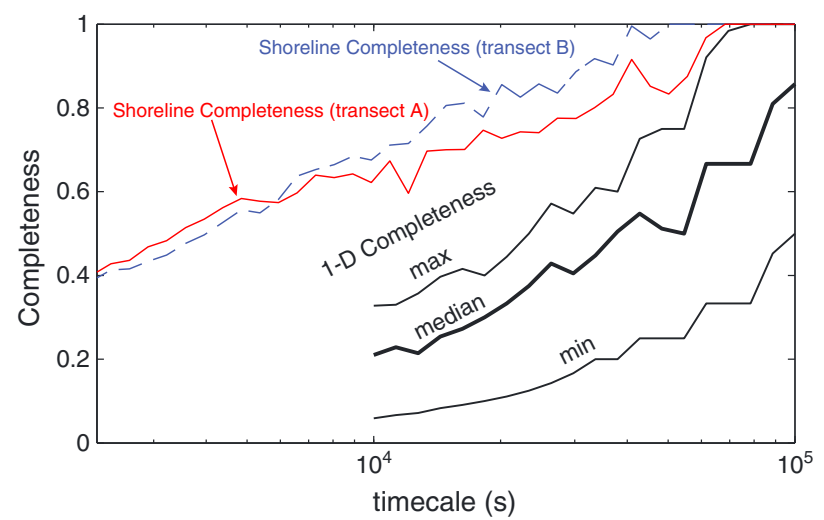

Figure 8. Cumulative distributions of shoreline completeness from transect $A$ and transect $B$ calculated using equation (3), and one-dimensional stratigraphic column completeness determined from 13 topographic scans across the delta calculated using equation (1). Because one-dimensional completeness was calculated at every scanned topset location, only the minimum, median, and maximum completeness values are shown for a given timescale. Minimum timescale for one-dimensional completeness is set by the characteristic time between topographic scans. considered to be the minimum timescale over which completeness should be analyzed. At this timescale, shoreline was $\sim 40 \%$ complete in both transects analyzed.

Shoreline completeness was compared to one-dimensional completeness of the deposit measured from 13 high-resolution topographic scans. Completeness was assessed at every scanned point $(n=405081)$ on the delta topset in plan view that was exposed (i.e., above sea level) for each of the scans. The minimum, median, and maximum calculated values of one-dimensional completeness from these locations are also shown in Figure 8. One-dimensional completeness also approaches 1 as the timescale reaches the length of the experiment. As the timescale of analysis decreases, however, these distributions decrease more rapidly than shoreline completeness. At the

characteristic timescale between topographic scans, the minimum timescale considered reasonable to assess completeness $\left(1.28 \times 10^{4} \mathrm{~s}\right)$, the median one-dimensional completeness was $21 \%$. At $t=3 \times 10^{4} \mathrm{~s}$, the maximum one-dimensional completeness was $54 \%$ and the median was $40 \%$, whereas calculated shoreline completeness was significantly higher- $75-80 \%$ in both transects. At this timescale, the shoreline is 88-100\% more complete than the median one-dimensional section.

In both analyzed sections, substantial portions of the geomorphic shoreline trajectories were missing due to erosion that occurred primarily during base level fall. During base level lowstand, incision along the delta top, and deposition at the delta front, were localized and relatively stationary close to transect $A$. This resulted in both enhanced removal of antecedent stratigraphic sequences, as well as enhanced preservation of lowstand shorelines during this period. Conversely, at locations where lowstand channels were not as prominent (e.g., along transect B), erosion did not influence antecedent stratigraphic sequences as significantly. However, lowstand shoreline positions are also not as well represented due to nondeposition. This likely would have been even more pronounced had sections further to the left of transect B been analyzed, as transect B still received some sediment due to transverse transport systems during lowstand. In the forward models described below, we demonstrate how details of delta topset reworking can be important to the resulting stratigraphic completeness.

\subsection{Modeling}

\subsubsection{Synthetic Trajectories}

In order to validate and demonstrate the distinction between the two end-member models, we developed a set of four simplified, synthetic input shoreline trajectories demonstrating different scenarios for shoreline migration (see Figure 9). These trajectories represent (a) a dominant signal of base level rise with sinusoidal regression/transgression, (b) a counterclockwise loop, (c) a clockwise loop, and (d) a dominant signal of regression with sinusoidal base level fall/rise. Normalized temporal and spatial scales were used to make all model results directly comparable. Using consistent number of positions and constant input topset-foreset geometries $\left(3.5^{\circ}\right.$ and $33^{\circ}$, respectively), these model results elucidate the modeled completeness response to a range of input trajectories.

For the case of simple aggradation accompanied by fluctuations in the horizontal position (sinusoidal in the example shown-see Figure 9a), both models yield identical completeness curves, wherein the shoreline completeness is always $100 \%$ at timescales equal to or greater than the characteristic timescale between input shoreline positions. Completeness remains $100 \%$ because the shoreline is never eroded in this trajectory. The counterclockwise loop (Figure 9b) is initiated by a period of aggradation, followed by a 

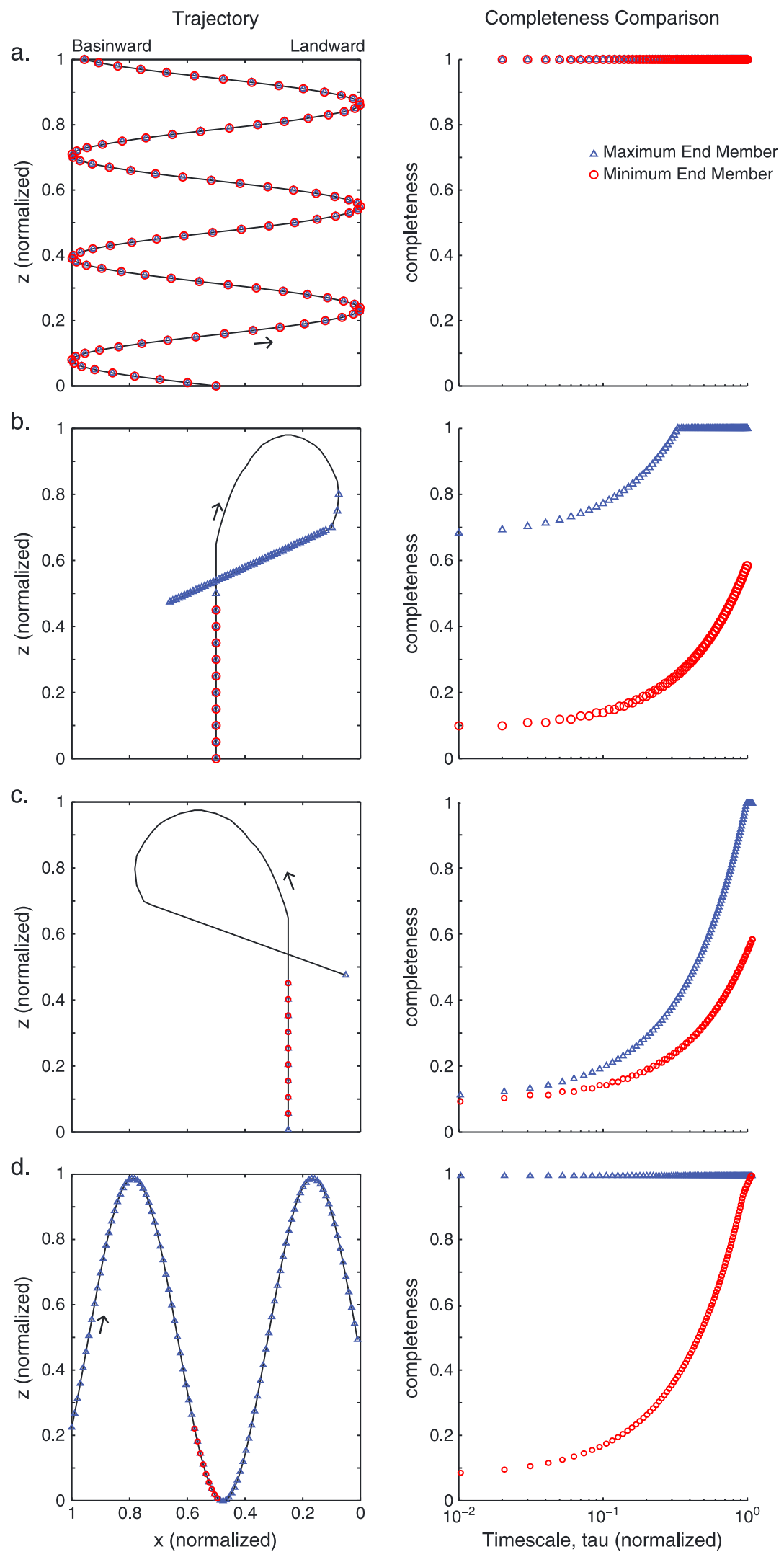

Note: $10 x$ vertical scale exaggeration

Figure 9 


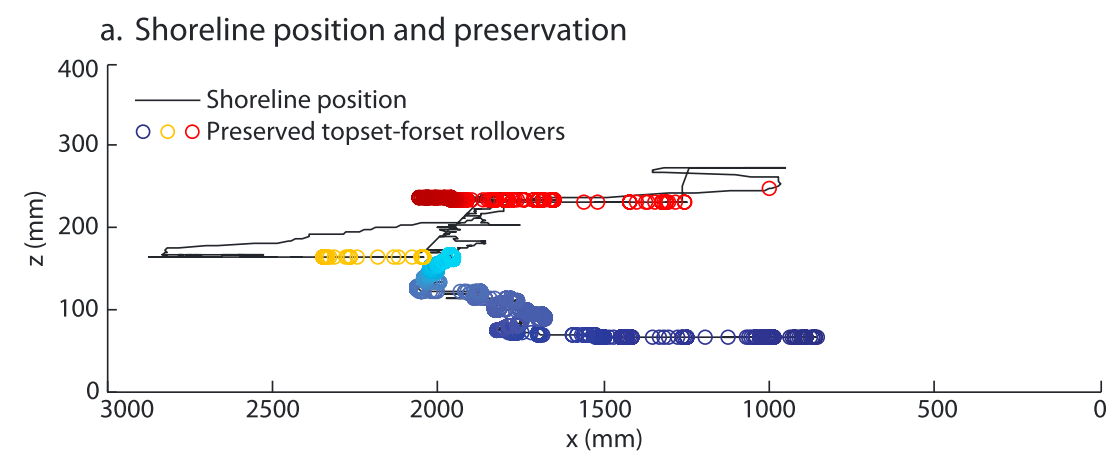

b. Preserved Strata (at 30 second time resolution)

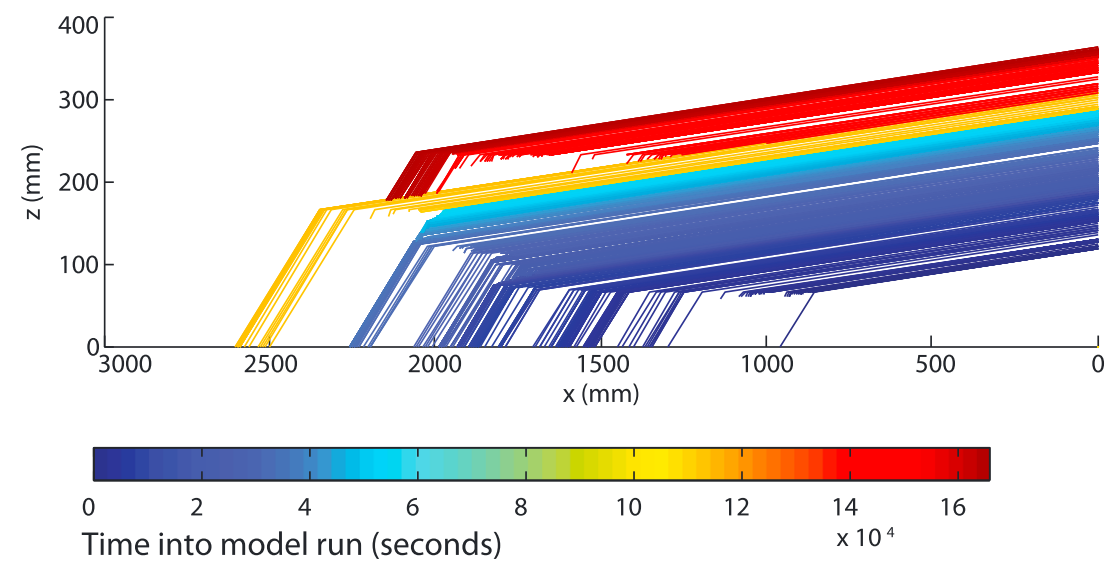

Vertical Exaggeration (both plots) $=2.5 \mathrm{x}$

Figure 10. Location and timing of (a) preserved shoreline markers and (b) example stratigraphy from a delta model run using the observed shoreline $x(t)$ and $z(t)$ trajectory from the SAFL delta experiment along transect A. The modeled stratigraphy under the minimum completeness model (Model \#1) in Figure $10 \mathrm{~b}$ evaluates preservation at a temporal resolution of $30 \mathrm{~s}$. The modeled and experimental stratigraphy are roughly similar with the two biggest differences being (1) the modeled stratigraphy does not record the furthest prograded strata that formed after the base level drop (yellow strata, $\sim 11 \times 10^{4} \mathrm{~s}$ ) and (2) the modeled stratigraphy records more of the last progradational event (red strata, after $15 \times 10^{4} \mathrm{~s}$ ).

transgressive period associated with first aggradation then degradation, and finally followed by a period of regression and lowering was applied. Completeness-timescale relations both increase linearly. Completeness curves, however, are significantly different between both models, with the maximum completeness end-member producing significantly higher completeness estimates and reaching $100 \%$ completeness at normalized timescale of 0.33 . In the third synthetic case presented (Figure 9c), completeness is markedly similar between both models, increasing linearly over all timescales. For the fourth case of transgression with base level fluctuation applied as a simple sinusoid (see in Figure 9d), model results are markedly different, with the maximum completeness end-member model resulting in $100 \%$ completeness across all timescales, while the minimum completeness end-member model yielded significant erosion of the shoreline record and very low values of stratigraphic completeness, increasing linearly over all timescales.

4.2.2. Experimental Trajectories

To further evaluate expected completeness outputs for both models, we ran each model using observed shoreline $x(t)-z(t)$ trajectories from experimental cross sections (we present model comparisons from transect A herein). Simulated cross sections/trajectories were produced for comparison to physical

Figure 9. Comparison of shoreline preservation (left column) and completeness-timescale relations (right column) for the two end-member models from synthetic input shoreline trajectories: (a) base level rise with sinusoidal regression/transgression, (b) regression with sinusoidal base level fall/rise, (c) a clockwise loop, and (d) a counterclockwise loop. Spatial and temporal inputs and axes are normalized for comparison, and all input shorelines are given equal characteristic timescale $(0.001)$ between successive shoreline positions. Arrows indicate the direction of the input trajectory. Note: a 10X vertical exaggeration between normalized axes is applied such that the scale indicated in horizontal (0-1) represents $10 \mathrm{X}$ the equivalent scale in the vertical. 
observations (Figure 10: minimum completeness model results) parameterized with an average of the observed topset and foreset slopes ( $3.5^{\circ}$ and $33^{\circ}$ from the horizontal, respectively). Completeness analyses were run for both real sections and synthetic model results to generate comparable stratigraphic sequences as well as timescale-completeness relationships (see Figure 10).

While the resolution of topset-foreset rollovers in both field and experimental sections are controlled by thicknesses of stratal packages, our models generate strata or shoreline positions at the timescale of the input geomorphic shoreline trajectories set, in this case, by the frequency of overhead imagery. From analysis of experimental delta stratigraphy (see Figures 6 and 7), we resolved 73 and 74 topset-foreset rollovers from transects $A$ and $B$, respectively, while the model output preserves nearly 1500 rollovers from each. Modeled stratigraphy allows for the creation of a new shoreline marker every $30 \mathrm{~s}$, while in reality a stratal package is only created through self-organized separation between the anthracite and quartz grains. This process appears to have a much longer characteristic timescale than the $30 \mathrm{~s}$ modeled intervals: on average, a new stratal package was created only once every $2.24 \times 10^{3} \mathrm{~s}$, with substantial variability.

\subsection{Subsampling}

Subsampling of experimental shoreline trajectories was undertaken to determine the influence of subsampling methods on the resultant trajectories in order to understand the appropriateness of specific methods to our stratigraphic sequence. For the first method ("spatial/seismic method") we sampled using the characteristic spacing of stratigraphic shoreline positions from the experimental transects $(\sim 25 \mathrm{~mm})$. For the remaining two filtering methods (biggest steps and random), the number of observed shoreline positions was used. Completeness was then calculated over a range of timescales to develop completeness-timescale curves for both of the model cases for comparison. These results and their comparison to experimental data are discussed further in section 5.4.

\section{Discussion}

\subsection{Shoreline Versus 1-D Completeness}

It has been hypothesized that stratigraphic completeness, as a description of the analyzed stratal volume's likelihood of preserving a record of sedimentation over some timescale, must increase with higher dimensions of observation as dictated by the principles of conservation of sediment mass [Sadler and Jerolmack, 2014]. Sadler and Jerolmack [2014] propose that the global product of aggradation and progradation therefore should be temporally invariant, which would require this record to be complete at all timescales and should mimic the global production of sediment through erosion. Direct measurements in natural systems of these parameters are difficult, if not impossible over large spatial and temporal scales, and controlled laboratory deltas provide an exceptional opportunity to test these hypotheses. The position of the shoreline in two-dimensional transects on a delta provides a simplified record of both the local aggradation and progradation of the depositional system (i.e., the shoreline migration rate is one dimensional with 2 degrees of freedom), and observations at this dimensional scale should therefore result in more complete sections over all timescales.

In both observed cases presented herein, the two-dimensional metric of shoreline completeness is significantly higher than the one-dimensional metric derived from any single stratigraphic columnar section over all timescales analyzed (Figure 8). In the context of stratigraphic and biostratigraphic analysis, where one is interested in the most complete record possible at the timescale of interest, this finding provides validation of the hypothesis that completeness increases with higher dimensions of analysis. In stratigraphic research focused on determining the kinematics of the sedimentary surface (i.e., aggradation, progradation, and shoreline migration), or rates of biological evolution from the biostratigraphic record, the most complete understanding of past rates is gained from analyses of the least incomplete stratal volumes. Stratigraphic research emphasizing such rates, therefore, should necessarily involve the highest dimensions of observation possible.

\subsection{Experimental Completeness Comparison}

Based on the considerations outlined in section 1, we anticipate that there may be some difference in the shoreline completeness at various timescales recorded on the delta based on local erosive and depositional processes. Completeness-timescale relations appear remarkably similar between the two 
transects analyzed (see Figure 8). This is enticing when considering that through much of the major period of experimental base level lowstand, the topset was more heavily eroded along transect $A$ than along $B$ (see Figures 5-7). It is possible that this is a result of the dip-parallel nature of the sediment routing system, such that periods of topset erosion that would remove shorelines from the record and result in depressed completeness values in a single transect are perhaps compensated for by the contemporaneous progradation basinward along the same axial transect. In transects slightly off axis of the main sediment routing system, topset erosion is not as prevalent, resulting in elevated preservation potential, while at the same time, fewer new shoreline positions are created downdip. This is encouraging, as it indicates that local, autogenic erosive and sediment routing effects may not feature so prominently in overall completeness of a transect as to completely overwhelm the expected, averaged response to the imposed base level history. This observation has potential implications in the way that completeness in twodimensional systems might be conceptualized and would warrant further exploration in dip transects where the nature of sediment erosion/delivery during lowstand was more significantly different than between the two transects analyzed.

However, there are some higher-order differences between the two curves. At timescales shorter than approximately $4 \times 10^{3} \mathrm{~s}$, the shoreline completeness values along section $\mathrm{A}$ are systematically a few percent higher than those of section $B$. However, above this timescale, the completeness values of section $B$ begin to exceed those of section A, with the result that section $B$ eventually becomes $100 \%$ complete at $5 \times 10^{4} \mathrm{~s}$, $\sim 29 \%$ faster than section $A$. We interpret these differences as expected effects of the known variability in incision history between the two sections. At short timescales, the two curves are largely similar because sediment is mainly delivered through radial channels on the delta top. While part of the history has been erased from section $A$, at short timescales this is compensated for by redeposition of this material largely along the same section line. The few percent elevation of completeness at these scales seen in A probably reflects net delta transverse transport of material into the section of $A$ during the lowstand-note that Figure 8 shows material entering this cross section from river left in the form of a lowstand progradational lobe. However, at longer timescales, the removal of a larger discrete portion of the depositional history in section A becomes more apparent.

For a section to be $100 \%$ complete under our methods, the analysis timescale, $\Delta t$, from equation (3) must exceed the longest continuous period of nondeposition or erosion present in the section. The removal of a whole contiguous part of the stratigraphic record in section A thus depresses its completeness values at longer timescales compared to section $B$, which did not experience similar, significant incision.

\subsection{Model Response to Shoreline Trajectories}

The comparison of synthetic trajectories run through the minimum and maximum completeness end-members can be used to develop a conceptual understanding of how shoreline trajectories affect completeness. When a simple aggradational trajectory is modeled with cyclical transgression/regression applied (Figure 9a), both models are fully complete at all timescales above the characteristic timescale between preserved shorelines. This type of trajectory is characteristic of many highly aggradational systems such as the experimental delta of Kim et al. [2006].

Loops, wherein shoreline positions are observed to occupy a space below and landward of previous positions (i.e., the position of a sediment-water interface within space that was once filled with sediment) that end in either progradation or retrogradation result in stratigraphic trajectories with some portion of the original trajectory absent from the stratigraphic record in both models (see Figures 9b and 9c). How the maximum completeness end-member model treats these types of trajectories relative to the minimum completeness end-member depends on the exact geometry of the trajectory. The directionality of the loop relative to the $x$ and $z$ dimensions is a strong control on modeled stratigraphic preservation, as trajectories ending landward and below the loops result in maximum erosion in both end-member models (e.g., Figure 9c), whereas those ending in aggradational or progradational trajectories result in significantly different outcomes (e.g., Figure 9b). Removal of the sedimentary record by this process is reflected in the geomorphic shoreline trajectories in the two experimental transects described in this paper.

Finally, when $z$ is modeled as a sinusoidal fluctuation about $x$, the maximum end-member model is fully complete, while the minimum end-member removes previous shoreline locations during each base level 
a. Spatial/Seismic Sampling

Completeness-Timescale Relationship

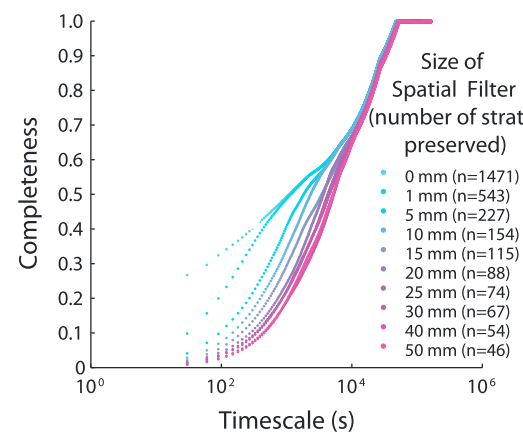

Example Preserved Strata $(n=46)$

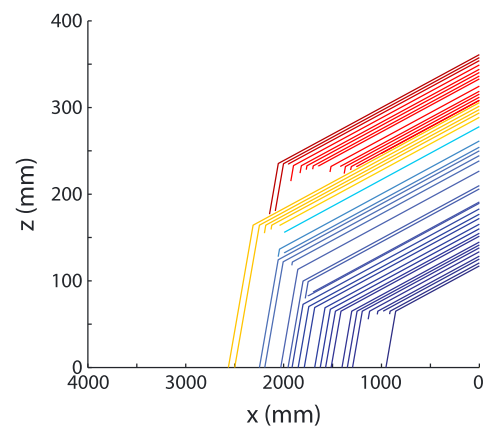

b. Biggest Steps Sampling
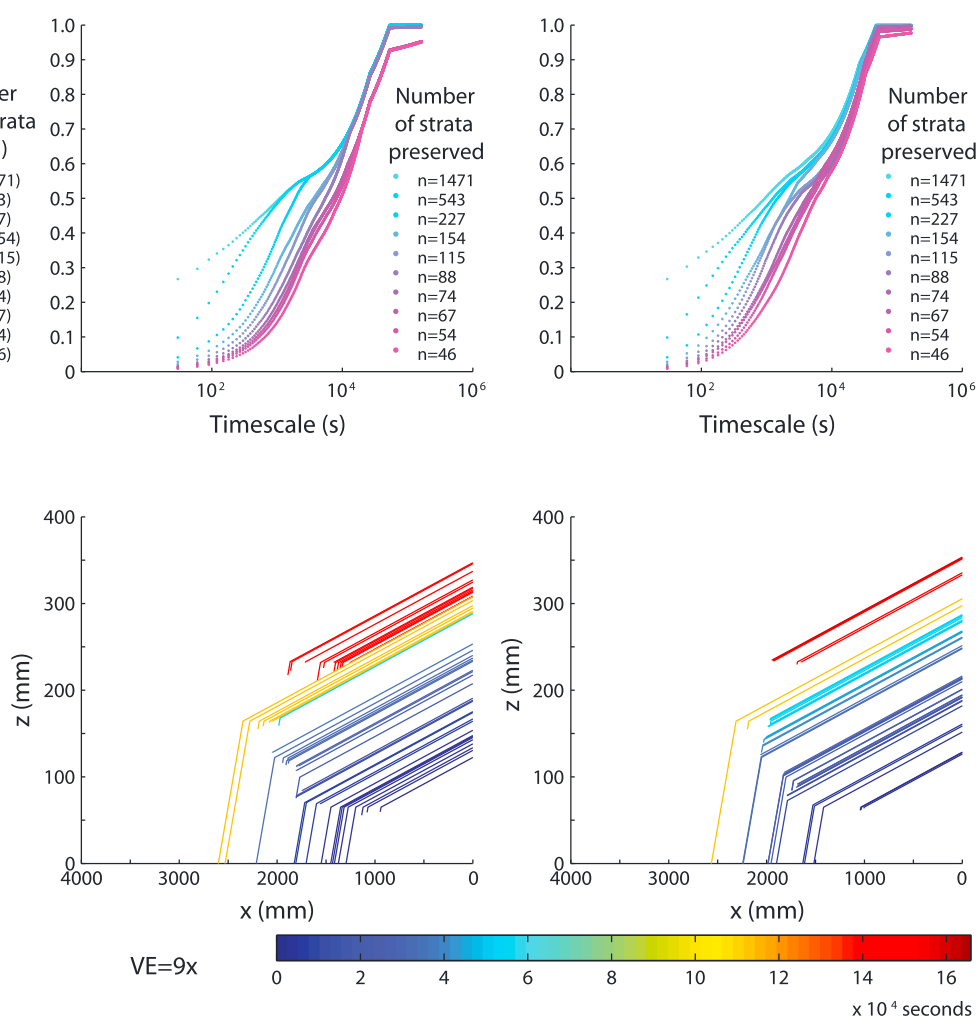

Figure 11. Completeness-timescale relationships (top row) and example stratigraphy (bottom row) for the trajectory along transect $A$ for three different methods of sampling the stratigraphy described in Figure $8 \mathrm{~b}$ (from transect A). The modeled stratigraphy (Figure $8 \mathrm{~b}$ ) evaluates preservation of a shoreline marker every $30 \mathrm{~s}$. Three sampling schemes evaluate how the completeness-timescale relationship changes. (a) The spatial/seismic sampling samples at a regular spatial interval and is meant to simulate seismic observations. Each spatial interval chosen results in a different number of selected strata, $N$. We use the same set of $N$ for the following two filters. (b) Preferentially selects strata where the distance between preserved strata is large, this biases the record toward times when sedimentation rates in the cross section were high. (c) The random sampling method randomly chooses which strata to sample. The completeness-timescale relationship depends more on the number of samples $(N)$ than the sampling method. VE indicates $9 \mathrm{X}$ vertical exaggeration.

fall (Figure 9d). This type of shoreline progradation may describe several real-world scenarios in which deltas and continental margins prograde under the presence of varying relative sea level. The relative difference between the completeness values of the two end-member models in this scenario depends heavily on the magnitude of the base level cycles relative to the progradational distance and the angle of the topset.

\subsection{Comparisons of Model Results to Experimental Observations}

The predicted minimum versus maximum completeness relationship over all timescales between the two end-member models appears to hold generally. However, when subsampled to the corresponding number of stratigraphic shoreline positions as observed in the experimental transects, significant differences arise depending on the method of downsampling (see Figures 11 and 12). The first method of spatial/seismic sampling (Figures $11 \mathrm{a}$ and 12a) results in an appropriate completeness-timescale relationship when compared to the measured shoreline completeness; however, it fails to accurately reproduce the observed stratigraphic positions of the shorelines. The biggest steps filter (Figures $11 \mathrm{~b}$ and $12 \mathrm{~b}$ ) appears to result in model completeness curves that do not adequately represent either real stratigraphic completeness or result in predicted relations between the minimum completeness (Model \#1) and maximum completeness (Model \#2) end-member model outputs. The third, randomly sampled spatial filter (Figures 11c and 12c) results in a more accurate representation of both stratigraphic completeness and shoreline positions under known conditions of this section. This is likely a consequence of the detailed level of analysis we were able to perform on these transects, through controlled laboratory conditions and fine-scale imagery (to grain scale). 

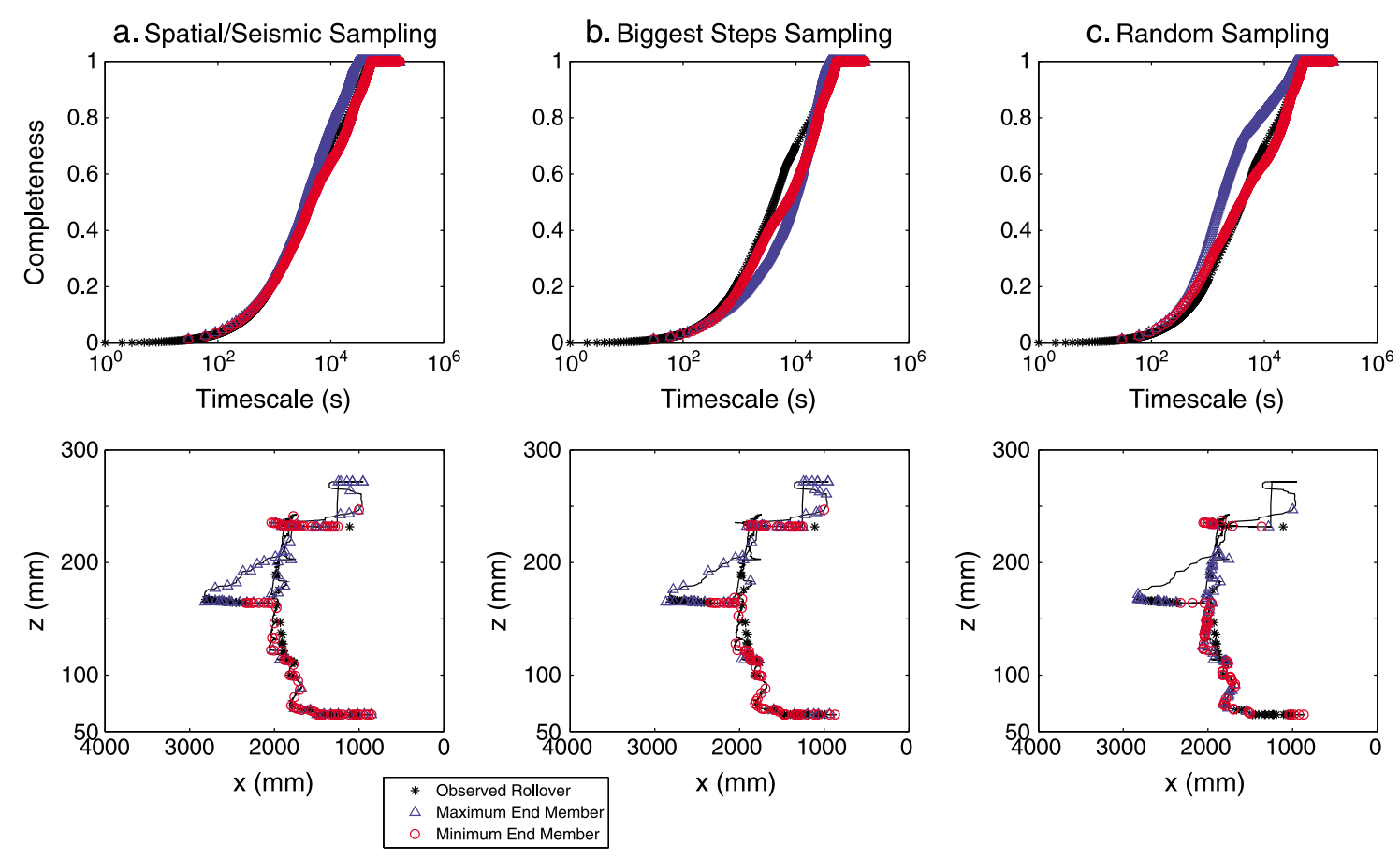

Figure 12. Completeness-timescale relationships for each of the two end-member models compared with stratigraphic results from transect $A$ (top row), with the model output and experimentally observed shoreline positions (bottom row). Model results are subsampled to 73 shoreline positions, using the three methods described above, to be comparable to the observed stratigraphy. Note that in transect A, where erosion of the topset occurs during lowstand, models are predicted to give similar values at all timescales, which is shown to be the case.

We believe we were able to capture all of the strata present, so no systematic bias in stratal thickness was present in the sampling procedure.

However, in a field-based or seismic study using similar techniques, we might expect the documented differences between sampling styles to start to appear in analyses. In particular, we note that our modeling suggests an observational bias in the field toward the thickest, most prominent beds will lead to calculated shoreline completeness values which are artificially depressed. Cases where such bias might be expected-for example, remotely sensed data drawn from field/aerial photographs or binocular workshould be avoided for the construction of reliable completeness estimates. Conversely, however, introducing a consistent, characteristic thickness between sampled horizons in the data-as might be the case if performing analyses on a seismic section-appears to be much less problematic, and resulting values will match "true" completeness fairly closely. Encouragingly, this result suggests that completeness established from seismic sections could be relatively unbiased and reliable.

\subsection{Independence of Models on Transport Dynamics}

Modeling the generation of stratigraphic shorelines from information derived exclusively from the kinematics of geomorphic shoreline trajectories allows for explicit solutions to stratigraphic completeness in twodimensional down dip sections. The most important feature of this approach is the independence of models from the complex nature of sediment transport and delta top fluvial dynamics [e.g., Muto and Steel, 1997, 2002; Kim et al., 2006]. These processes, which are dynamic and involve nonuniform cross-dip transport of sediment [e.g., Straub and Esposito, 2013], result in the inability to model stratigraphic development with continuity equations [Kim et al., 2006; Wolinsky, 2009] in a two-dimensional sense, as sediment mass conservation is not maintained in any two-dimensional section. Thus, independence from assumptions of sediment mass conservation is a necessary and powerful component of the development and implementation of the forward models presented here.

The absence of explicit dependence on sediment transport in the developed models potentially enables them to be applied in order to back out transport conditions from shoreline trajectories and shoreline 
completeness curves, given a complete model for shoreline trajectory response to sediment flux. In the future, these models may be applied to multiple two-dimensional transects across a three-dimensional delta to produce a volume of stratigraphic shoreline positions and stratigraphic completeness curves. In conjunction with known input sediment discharge and base level histories as well as conservation of sediment mass-derived models describing the shoreline response to such controls [Wolinsky, 2009], these transect sets could then be used to explicitly determine the routing of sediment in the three-dimensional sense across a delta top.

\section{Conclusions}

Comparisons of geomorphic and stratigraphic shoreline trajectories in the context of stratigraphic completeness provide a useful conceptual tool for the analysis of stratigraphic completeness in higher dimensions than previously applied. Applying the concept of stratigraphic completeness to a simplified two-dimensional framework (i.e., a shoreline trajectory that records both progradation and aggradation of the sedimentary surface provides a first approach to upscaling current thinking of completeness to higher dimensions). Experimental shoreline trajectories in two dimensions show higher proportions of stratigraphic completeness than comparable-timescale one-dimensional measurements. This result supports the hypothesis that completeness of any stratigraphic sequence should increase with higher dimensions of analysis as a result of increased likelihood of preservation of record within individual time intervals. Completeness-timescale relationships for shoreline trajectories in two experimental transects are also markedly similar, considering the differences in the distribution of erosion and deposition during base level lowstand. It is postulated that completeness analysis in a two-dimensional dip-parallel framework yields similar results across a system due to the downdip nature of sediment routing systems and the compensation of erosion by downdip progradation.

The forward models developed in this paper allow for the prediction of stratigraphic shoreline preservation from geometric and kinematic arguments, without explicitly requiring information on the primary geologic controls (e.g., sediment flux and relative sea level), allowing for a fully constrained range of solutions to individual input conditions; however, input trajectories alone only allow the exact determination of output stratigraphic trajectories under a limited range of conditions. Modeled completeness-timescale curves show very reasonable agreement with completeness-timescale relations determined from experimental stratigraphy when subsampled to produce a similar number of preserved shoreline positions. Such models simulating different observational methods (i.e., seismic, outcrop, and experimental) reveal that some styles of layer subsampling from a section can alter calculated completeness and determine whether model results reproduce the predicted relationship to directly measured completeness values. In particular, if a sampling technique acts to preferentially exclude thinner beds or those showing slower change, completeness can be significantly underestimated for an equivalent number of preserved shoreline positions. However, the kind of "characteristic spacing" sampling that might be expected from a seismic section or random sampling appears robust for completeness estimation.

Inverse solutions to determine higher-dimension completeness values from the stratigraphic record remain unresolved at this time. However, the development of forward modeling for delta shoreline completeness in two dimensions provides a potential framework from which these inverse models could be developed in the specific deltaic shoreline framework described herein. A series of synthetic shoreline trajectory analyses intended to provide a range of preserved shoreline position and completeness responses to varying input trajectories provides the necessary first steps toward approaching potential inverse solutions by describing a range of outcomes given a set of geologically plausible input conditions. We speculate that such inverse solutions may be derived only upon analysis of shoreline trajectories for systems in which substantial chronologic and stratigraphic control is available. However, understanding derived from experimental and theoretical evaluations of completeness responses to sedimentary processes in higher dimensions can provide valuable conceptual tools for the analysis of sedimentary basins. Finally, examination of various scenarios within the end-member forward models, in conjunction with further analyses of experimental deltas under varying conditions, may elucidate controls on the timescales at which stratigraphic completeness of shoreline trajectories approach $100 \%$ complete. Such analyses could potentially allow an understanding of timescales over which shoreline trajectories can be adequately analyzed to determine allogenic forcings from the stratigraphic record. 
Acknowledgments

Experiments were conducted at St. Anthony Falls Laboratory as part of the 2013 Summer Institute on Earth Surface Dynamics. We would like to thank the National Science Foundation and the National Center for Earth-surface Dynamics (NCED 2) for funding the Summer Institute (award NSF-EAR1246761). We thank the research staff at St. Anthony Falls Laboratory for setting up and running the experimental delta, especially Antoinette Abeyta and Aaron Ketchmark. This study benefitted greatly from discussions with Chris Paola, Efi Foufoula-Georgiou, Kyle Straub, Jean-Louis Grimaud, and Kevin Roche. J.B. Shaw is supported by an NSF Postdoctoral fellowship. K.R. Barnhart is supported by a NASA Earth and Space Science Fellowship (award NNX12AN52H). R.C. Mahon was supported by a ConocoPhillips Rocky Mountain Basin Graduate Study Scholarship. D.E.J. Hobley was supported through an NCED2 fellowship (award EAR-1246761). This work was partially supported by the University of Wyoming School of Energy Resources. We thank Wonsuck Kim, Daniel Mikeš, Alexander Densmore, and two anonymous reviewers for insightful commentary leading to a greatly improved manuscript. Experimental data used in this study, as well as all model codes and metadata, are available in the supporting information associated with this manuscript. Data and analysis code are also archived and made available through the Sediment Experimentalists Network Knowledge Base at www. sedexp.net. A supporting information file contains descriptions of all data sets and model codes included with this manuscript (see supporting information Text S1).

\section{References}

Barrell, J. (1917), Rhythms and the measurement of geologic time, Geol. Soc. Am. Bull., 28, 745-904.

Dingus, L. (1984), Effects of stratigraphic completeness on interpretations of extinction rates across the Cretaceous-Tertiary boundary, Paleobiology, 10(4), 420-438.

Dingus, L., and P. M. Sadler (1982), The effects of stratigraphic completeness on estimates of evolutionary rates, Syst. Zool., 31(4), 400-412, doi:10.1093/sysbio/31.4.400.

Helland-Hansen, W., and G. J. Hampson (2009), Trajectory analysis: Concepts and applications, Basin Res., 21, 454-483, doi:10.1111/ j.1365-2117.2009.00425.x.

Helland-Hansen, W., and O. J. Martinsen (1996), Shoreline trajectories and sequences: Description of variable depositional-dip scenarios, J. Sediment. Res., 66(4), 670-688.

Henrickson, S., G. J. Hampson, W. Helland-Hansen, E. P. Johannessen, and R. J. Steel (2009), Shelf edge and shoreline trajectories, a dynamic approach to stratigraphic analysis, Basin Res., 21(5), 445-453, doi:10.1111/j.1365-2117.2009.00432.x.

Jerolmack, D. J., and P. Sadler (2007), Transience and persistence in the depositional record of continental margins, J. Geophys. Res., 112, F03S13, doi:10.1029/2006JF000555.

Kemp, D. B. (2012), Stochastic and deterministic controls on stratigraphic completeness and fidelity, Int. J. Earth Sci., 101, 2225-2238, doi:10.1007/s00531-012-0784-1.

Kim, W., and T. Muto (2007), Autogenic response of alluvial-bedrock transition to base-level variation: Experiment and theory, J. Geophys. Res., 112, F03S14, doi:10.1029/2006JF000561.

Kim, W., C. Paola, V. R. Voller, and J. B. Swenson (2006), Experimental measurement of the relative importance of controls on shoreline migration, J. Sediment. Res., 76, 270-283, doi:10.2110/jsr.2006.019.

Kim, W., C. Paola, J. Martin, M. Perlmutter, and F. Tapaha (2009), Net pumping of sediment into deep water due to base-level cycling: Experimental and theoretical results, in External Controls of Deep-Water Depositional Systems, vol. 92, edited by B. Kneller, O. J. Martinsen, and B. McCaffrey, pp. 41-56, SEPM Spec. Publ., Tulsa, Okla.

Lowenstein, T. K., M. C. Hein, A. L. Bobst, T. E. Jordan, T.-L. Ku, and S. Luo (2003), An assessment of stratigraphic completeness in climate-sensitive closed-basin lake sediments: Salar de Atacama, Chile, J. Sediment. Res., 73(1), 91-104, doi:10.1306/061002730091.

Maia, R. M.d. C., A. T. dos Reis, E.d. C. Alves, C. G. Silva, J. V. Guerra, C. Gorini, A. Silva, and R. Arantes-Oliviera (2010), Architecture and stratigraphic framework of shelf sedimentary systems off Rio de Janeiro State, Northern Santos Basin-Brazil, Braz. J. Oceanogr., 58, 15-29, doi:10.1590/S1679-87592010000500003.

Muto, T., and R. J. Steel (1997), Principles of regression and transgression: The nature of the interplay between accommodation and sediment supply: PERSPECTIVES, J. Sediment. Res., 67(6), 994-1000.

Muto, T., and R. J. Steel (2002), Role of autoretreat and A/S changes in the understanding of deltaic shoreline trajectory: A semi-quantitative approach, Basin Res., 14(3), 303-318, doi:10.1046/j.1365-2117.2002.00179.x.

Plotnick, R. E. (1986), A fractal model for the distribution of stratigraphic hiatuses, Paleobiology, 32, 885-890.

Rubin, D. M., and R. E. Hunter (1982), Bedform climbing in theory and nature, Sedimentology, 29, 121-138, doi:10.1111/j.1365-3091.1982. tb01714.x.

Sadler, P. M. (1981), Sediment accumulation rates and the completeness of stratigraphic sections, J. Geol., 89(5), 569-584, doi:10.1086/628623.

Sadler, P. M., and D. J. Jerolmack (2014), Scaling laws for aggradation, denudation and progradation rates: The case for time-scale invariance at sediment sources and sinks, in Strata and Time: Probing the Gaps in Our Understanding, edited by D. G. Smith et al., Geol. Soc. London Spec. Publ., 404, doi:10.1144/SP404.7.

Sadler, P. M., and D. Strauss (1990), Estimation of completeness of stratigraphical sections using empirical data and theoretical models, J. Geol. Soc., London, 147, 471-485, doi:10.1144/gsjgs.147.3.0471.

Schumer, R., and D. J. Jerolmack (2009), Real and apparent changes in sediment deposition rates through time, J. Geophys. Res., 114, F00A06, doi:10.1029/2009JF001266.

Schumer, R., D. J. Jerolmack, and B. McElroy (2011), The stratigraphic filter and bias in measurement of geologic rates, Geophys. Res. Lett., 38, L11405, doi:10.1029/2011GL047118.

Sheets, B. A., T. A. Hickson, and C. Paola (2002), Assembling the stratigraphic record: Depositional patterns and time-scales in an experimental alluvial basin, Basin Res., 14, 287-301, doi:10.1046/j.1365-2117.2002.00185.x.

Somerfield, C. K. (2006), On sediment accumulation rates and stratigraphic completeness: Lessons from Holocene ocean margins, Cont. Shelf Res., 26(17-18), 2225-2240, doi:10.1016/j.csr.2006.07.015.

Straub, K. M., and C. R. Esposito (2013), Influence of water and sediment supply on the stratigraphic record of alluvial fans and deltas: Process controls on stratigraphic completeness, J. Geophys. Res. Earth Surf., 118, 625-637, doi:10.1002/jgrf.20061.

Strauss, D., and P. M. Sadler (1989), Stochastic models for the completeness of stratigraphic sections, Math. Geol., 21, 37-59, doi:10.1007/ BF00897239.

Swenson, J. B., V. R. Voller, C. Paola, G. Parker, and J. G. Marr (2000), Fluvio-deltaic sedimentation: A generalized Stefan problem, Eur. J.Appl. Math., 11(5), 433-452.

Tipper, J. D. (1983), Rates of sedimentation, and stratigraphical completeness, Nature, 302, 696-698, doi:10.1038/302696a0.

Wetzel, A., and T. Aigner (1986), Stratigraphic completeness: Tiered trace fossils provide a measuring stick, Geology, 14(3), 234-237, doi:10.1130/0091-7613(1986)14<234:SCTTFP $>2.0 . C O ; 2$.

Wolinsky, M. A. (2009), A unifying framework for shoreline migration: 1. Multiscale shoreline evolution on sedimentary coasts, J. Geophys. Res., 114, F01008, doi:10.1029/2007JF000855. 